\title{
APPLICATIONS OF MACRO PHOTOGRAMMETRY IN ARCHAEOLOGY
}

\author{
D. Gajski ${ }^{\mathrm{a} *}$, A. Solter ${ }^{\mathrm{b}}$, M. Gašparović ${ }^{\mathrm{a}}$ \\ ${ }^{a}$ Faculty of Geodesy, Institute of Cartography and Photogrammetry, Kačićeva 26, Zagreb, Croatia - (dgajski, mgasparovic)@ geof.hr \\ ${ }^{\mathrm{b}}$ Archaeological Museum in Zagreb, Nikola Šubić Zrinski Square 19, Zagreb, Croatia - asolter@amz.hr
}

Commission V, WG V/2

KEY WORDS: Macro photogrammetry, archaeometry, calibration, cultural heritage, 3D model

\begin{abstract}
:
Many valuable archaeological artefacts have the size of a few centimetres or less. The production of relevant documentation of such artefacts is mainly limited to subjective interpretation and manual drawing techniques using a magnifier. Most of the laser scanners available for the archaeological purposes cannot reach sufficient space resolution to gather all relevant features of the artefact, such as the shape, the relief, the texture and any damage present. Digital photogrammetric techniques make measuring with high accuracy possible and such techniques can be used to produce the relevant archaeometric documentation with a high level of detail. The approaches for shooting a good macro photograph (in the photogrammetric sense) will be explored and discussed as well as the design of a calibration test-field and the self-calibration methods suitable for macro photogrammetry. Finally, the method will be tested by producing a photorealistic 3D-model of an ancient figurine.
\end{abstract}

\section{INTRODUCTION}

3D-digitalisation technology nowadays is demanding task for almost every museum, which wants to improve present documentation of artefacts kept and presented to visitors. The accurate and in detail faithful 3D-model do not just improve the present documentation on the way, it is more accurate or more faithful comparing to previous documentation, but it adds some new valuable information about artefacts, which weren't accessible by traditional documenting approaches (i.e. textures). Beside restoration and valorisation purposes, 3D-models are often intended to be used as virtual artefacts stored in digital libraries. These can be reached from a remote site by world wide web technologies, thus be accessible for exploration and investigation without space/time limits, usually provoked by museum's daily routines. Although archaeometry benefits from many hardware and software solutions, dedicated to digitising archaeological artefacts, there are still many challenges in producing of top-quality 3D-model of particular artefacts, concerning its shape, size, transparency, and reflectivity (Guidi et al., 2013). Such issues motivate scientists to find new approaches concerning the methodology of 3D-digitising and 3D-modelling (Remondino et al. 2013) as well as the new software solutions (Remondino et al. 2012). As a most reliable method to collect 3D-data of an archaeological artefact, the triangulation laser scanner is already well established. However, the importance and feasibility of photogrammetry are growing continuously, and now is the best alternative method for 3Ddigitizing of archaeological artefacts, because of following important features: the accuracy and level of details are strictly controlled by imaging scale and quality of the camera. The very short time is needed to collect data, so artefact can be fast returned to exposition. Image-based reconstruction method suffers from bad results in the case of unstructured, monochrome, translucent, reflective and self-resembling surfaces, which makes the use of laser scanner inevitable.

Small artefacts, just a few centimetres per dimension or even less, are by 3D-digitalisation out of scope, because the laser scanner or even photographic camera with the standard lens cannot reach enough good accuracy and faithfulness of 3Dmodel comparing to the original. Image-based reconstruction has the potential to do the job well. The artefact should be photographed by use of macro equipment, to reach enough big imaging scale, where should be avoided the issues that could cause the bad results.

\section{MACRO PHOTOGRAPHY}

There are several definitions of term "macro photography". Macro photography is extreme close-up photography, usually of very small subjects, in which the size of the subject in the photograph is greater than life size (though macro photography technically refers to the art of making very large photographs).(Saxby, 2010)(Freeman, 2010) By some definitions, a macro photograph is one in which the size of the subject on the negative or image sensor is life size or greater.(Erez, 2012). The term "life size" corresponds to 1:1 imaging scale of the subject to the image plane.

There are several ways, how to reach the imaging scale, close to 1:1 ratio. The best one, concerning the quality of taken image, is by use of macro lenses (Samaan et al. 2013) (Yanagi \& Chikatsu, 2010). On another hand, it is a most expensive method (from $\sim 500 \$$ for the entry-level lens to $\sim 2000 \$$ for the professional macro lens).

The extension tube set could be the cheaper alternative to macro lenses. However, the following disadvantages have to be considered:

1. the depth of field is strongly reduced,

2. the intensity of the illumination at the image plane is decreasing strongly by increasing the distance of the lens to the image plane.

The quality of photographs has the biggest impact on the quality of final 3D- model. That's why the choosing of appropriate equipment and its setting should be done with the biggest attention. Simple mathematical relations can help us to do the 
job well. Let start from the well-known relation of optical conjugation:

$$
\frac{1}{a}+\frac{1}{b}=\frac{1}{f}
$$

where

$\mathrm{a}=$ distance from object's principal plane to the object

$\mathrm{b}=$ distance from image principal plane to the image

$\mathrm{f}=$ focal length

The denominator of the imaging scale ' $\mathrm{s}$ ' is:

$$
s=\frac{a}{b}
$$

From (1) and (2) follows:

$$
a=f(1+s) ; \quad b=f \frac{1+s}{s}
$$

The formulae for near and far limit of acceptable sharpness are (Kraus, 2004)

$$
a_{n, f}=\frac{a f^{2}}{f^{2} \pm \frac{f}{d} c(a-f)}
$$

where $\quad a_{n}=$ near limit of acceptable sharpness $\mathrm{a}_{\mathrm{f}}=$ far limit of acceptable sharpness $\mathrm{a}=$ subject's distance $\mathrm{c}=$ circle of confusion (acceptable sharpness) $\mathrm{f} / \mathrm{d}=\mathrm{f}$-stop of objective lens

By combining (3) and (4) finally we get:

$$
a_{n, f}=\frac{f^{2}(1+s)}{f \pm \frac{f}{d} c s}, \quad \text { DoF }=a_{f}-a_{n}
$$

$$
\text { where } \quad \text { DoF }=\text { Depth of field }
$$

The depth of field is the most critical parameter in macro photography. Analysing the expression for depth of field (5), it becomes clear that the depth of field doesn't change by changing the focal length of objective if we keep the imaging scale constant. The depth of field is influenced only by imaging scale, f-stop number and diameter of the circle of confusion (acceptable sharpness).

For imaging in scale $1: 1, \mathrm{f}$-stop $=\mathrm{f} / 22$, and $\mathrm{c}=0.005 \mathrm{~mm}$, the DoF is just $0.44 \mathrm{~mm}$. Keeping all parameters the same like in the previous example and changing just the $f$-stop=f/32, the $D o F$ changes to $0.64 \mathrm{~mm}$. Using extending tubes in very close range photogrammetric applications is reasonable just for very shallow objects. The up-to-date macro lenses do not have so shallow depth of field, like the extension tubes.Therefore, they are much more suitable for photogrammetric applications.

\section{CASE STUDY}

\subsection{Ancient Amber Figurine}

To test the production of 3D-model based on macro photographs, the artefact nr.15441 (as catalogued in the museum of archaeology in Zagreb, Croatia) is chosen. It is the ancient amber figurine of the female head profile, excavated from grave nr.47 in Kompolje, and it has the interesting historical background.

In the early Iron Age period (8th - 4th century BC) the broader region of Lika, Croatia was settled by people known as the Iapodes although we can consider the end of Late Bronze Age (10th century BC) as the time of the first emergence of the Iapodian group. The Iapodes, initially a group of kindred tribal communities that gradually grew into a nation, are characterised by an identical material and spiritual culture - the method of building fortified settlements, burials and beliefs. Although the borders of their territory changed through time, the central Iapodian territory encompasses Lika and Ogulin-Plaška valley with part of Gorski Kotar and Kordun, but the Iapodes spread to the area of north-western Bosnia.

Amber occupies a particular place in the Iapodian culture. The amber found at the Iapodian sites originates in the Baltic, from where it crossed Europe via the so-called Amber routes and reached Adriatic. Out of all amber finds stands out the Grave 47 from Kompolje, not so much for the quantity but rather for the beauty of amber shaped figurines. Among the finds from Grave 57 were three beads shaped as women heads, a bead in the shape of a man's head and a swan. These items remind of the Greek myth of the young god Phaeton.

\subsection{The methodology}

Analysing the extents of the object $(30 \times 20 \times 5 \mathrm{~mm})$ and considering formulae (5) the imaging scale and needed equipment was chosen. The object will be imaged at image scale 1:2, by NIKON D90 photo camera. The objective lens is the standard one NIKKOR $35-105 \mathrm{~mm}$. The extending tube will be $17 \mathrm{~mm}$ long. Before taking photos the focus and zoom were locked. The calibration of camera equipped with lens and extension tube was done by using Matlab software "calibration tools" (Figure 1). The distortion of the camera was determined by using the well known Brown distortion model.

According to the extents of the object, the calibration plate was designed.

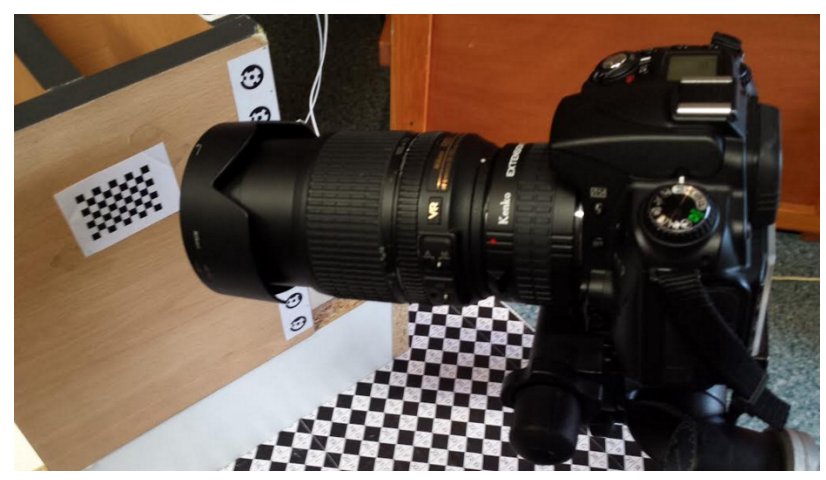

Figure 1. Camera with extension tube at the calibration field

Twelve photographs were taken from each side of the amber figurine. They were taken from different positions, evenly distributed on the same distance from figurine. 


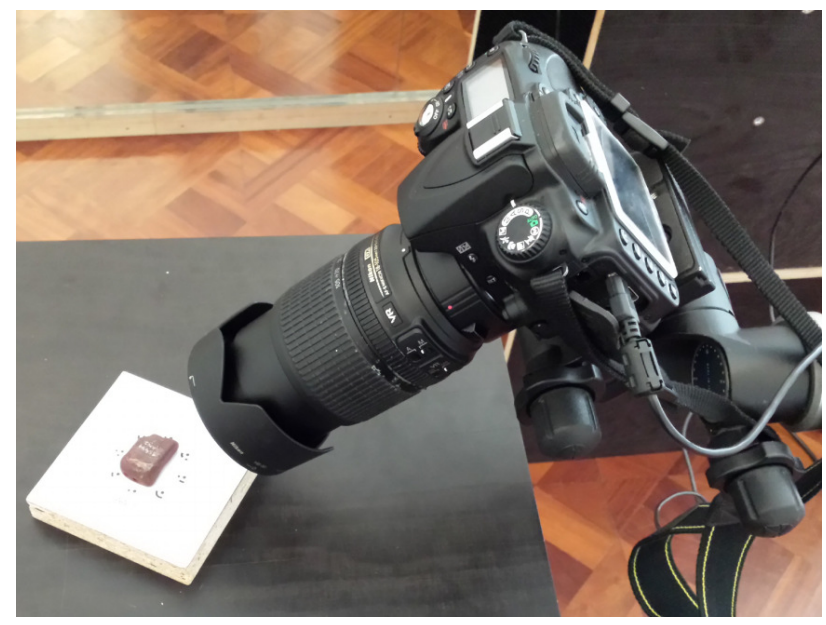

Figure 2. Photographing of the ancient amber figurine.

The calibration plate has eight binary coded photogrammetric signals. During the reconstruction of 3D-model the software recognises the binary-coded signals, measures them and records the image coordinates of them at every image where they are visible. The 3D-reconstruction was done by dividing images into two groups, one per each side. On that way, we could use the control points at each side.

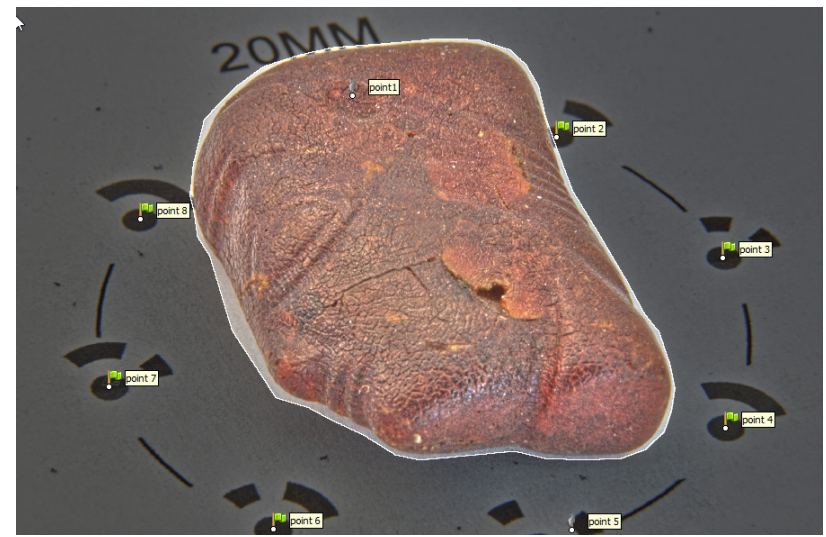

Figure 3. Image of figurine during measuring of control points.

At the end of phototriangulation the standard deviation at control points in reference coordinate system, as well as in image coordinate system are given in table below:

\begin{tabular}{|l|l|l|l|l|l|l|}
\hline Label & X error $(\mathrm{m})$ & Y error $(\mathbf{m})$ & Z error $(\mathbf{m})$ & Error $(\mathbf{m})$ & Projections & Error $(\mathbf{p i x})$ \\
\hline point 1 & 0.000015 & -0.000017 & -0.000015 & 0.000027 & 2 & 1.538073 \\
\hline point 11 & 0.000022 & -0.000059 & 0.000009 & 0.000063 & 5 & 1.752190 \\
\hline point 13 & 0.000019 & -0.000004 & -0.000001 & 0.000019 & 6 & 2.201523 \\
\hline point 15 & -0.000004 & 0.000047 & 0.000006 & 0.000048 & 6 & 2.162279 \\
\hline point 3 & 0.000001 & 0.000042 & 0.000007 & 0.000043 & 3 & 1.156394 \\
\hline point 5 & -0.000033 & -0.000003 & 0.000006 & 0.000034 & 6 & 0.985682 \\
\hline point 7 & -0.000026 & -0.000041 & -0.000002 & 0.000048 & 6 & 1.560933 \\
\hline point 9 & 0.000006 & 0.000034 & -0.000011 & 0.000036 & 5 & 1.145533 \\
\hline Total & $\mathbf{0 . 0 0 0 0 1 9}$ & $\mathbf{0 . 0 0 0 0 3 6}$ & $\mathbf{0 . 0 0 0 0 0 8}$ & $\mathbf{0 . 0 0 0 0 4 2}$ & 39 & 1.665922 \\
\hline
\end{tabular}

Table 4. Standard deviations at control points after adjustment

The table 4 shows that the accuracy (given by RMSE) of measured image coordinates is about 1-2 pix, that is, comparing to standard photogrammetric work, pretty low. It is obvious that the control points lies far out of the depth of field, defined by the diameter of the circle of confusion close to the pixel size in camera's image sensor (about 5 $5 \mathrm{~m}$ ). However, the reconstructed positions of control points in reference coordinate system are acceptable. The biggest total displacement error is $0.063 \mathrm{~mm}$ at control point nr.11; what for intended application seems acceptable (Table 4). After phototriangulation, the dense point cloud was reconstructed (54398 vertices), followed by interpolation of the model surface by applying the Triangular Irregular Network procedure, resulting in 107546 faces (Figure 5.a). Finally, the photorealistic textured model was generated. The pixel size at the model's surface is $11 \times 11 \mu \mathrm{m}$. (Figure $5 \mathrm{~b}$ )
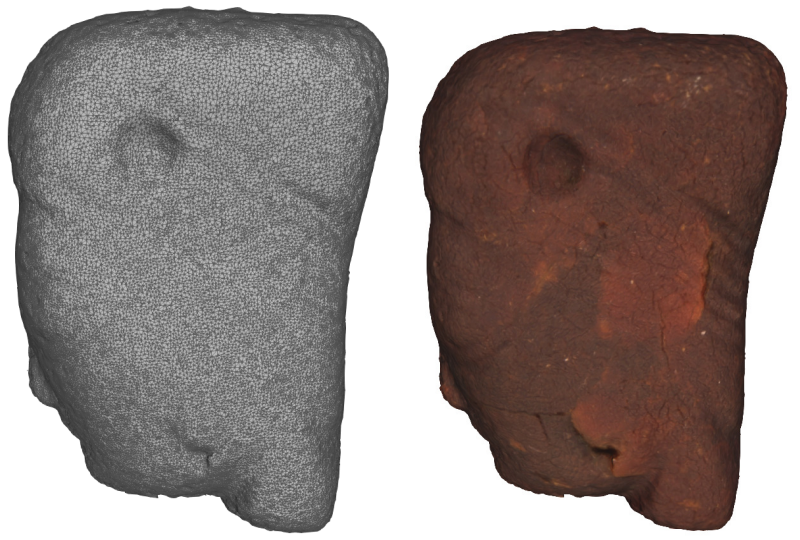

Figure 5. Ancient amber figurine. a) TIN-model; b) photorealistic textured model

\section{CONCLUSIONS}

The final result of the reconstruction of ancient amber figurine shows, it is possible and reasonable to produce the 3D-model of acceptable quality, by using of macro-photography followed by standard photogrammetric procedures. Taking a good macrophotography, suitable for photogrammetric reconstruction is challenging task. The selection of appropriate equipment is of the greatest importance. The objective lenses of the highest quality, dedicated to macro-photography can reach the best quality of the image. Just, they are pretty expensive and very often not accessible. This work shows that use of extension tubes in combination with the standard objective lens can give acceptable results, especially in the case of photographing the flat objects (i.e. coins).

\section{REFERENCES}

Bakarić, L., 2010. Sin Boga sunca. Kompolje, grob 47, Zagreb 2010.

Drechsler-Bižić, R., 1961. Rezultati istraživanja japodske nekropole u Kompolju 1955-1956. godine, Vjesnik Arheološkog muzeja u Zagrebu, 3.s., II, Zagreb, 1961, p.p.67-114

Freeman, M. 2010. The DSLR Field Guide: The Essential Handbook to Getting the Most from Your Camera. Focal Press. p.p. 30.

Saxby, G. 2010. The Science of Imaging: An Introduction (2nd ed.). CRC Press. p. 269

Guidi, G., Rodríguez Navarro, O., Gonizzi-Barsanti, S., Micoli,L.L., Russo, M., 2013: Quick textured mesh generation in Cultural heritage digitization. Proc. Built Heritage 2013, Conference - Monitoring Conservation and Management, pp.874-882. 
Kraus, K. 2004. Photogrammetry, Dummler Verlag, Bonn, Germany, 2004

Remondino, F., Del Pizzo, S., Kersten, T., Troisi, S., 2012. Low-cost and open-source solutions for automated image orientation - A critical overview. Proc. EuroMed 2012, Conference, LNCS 7616, pp. 40-54.

Remondino, F., Menna, F., Koutsoudis, A., Chamzas, C., ElHakim, S., 2013: Design and implement a reality-based 3D digitisation and modelling project. Proc. IEEE Conference "Digital Heritage 2013", Vol. 1, pp. 137-144.
Samaan, M., Heno, R., Pierrot-Deseilligny, M., 2013. CloseRange Photogrammetric Tools For Small 3D Archaeological Objects. International Archives of the Photogrammetry, Remote Sensing and Spatial Information Sciences, Volume XL-5/W2, 2013, XXIV International CIPA Symposium, 2 - 6 September 2013, Strasbourg, France

Yanagi, H., Chikatsu, H., 2010. 3D Modelling of small objects using macro lens in digital very close range photogrammetry, International Archives of Photogrammetry, Remote Sensing and Spatial Information Sciences, Vol. XXXVIII, Part 5 Commission V Symposium, Newcastle upon Tyne, UK. 2010 